\title{
Extração de maior valor dos sistemas de informação voltados para redes: importância do domínio semântico dos protocolos de comunicação pelos atores
}

José Osvaldo De Sordi

Docente-pesquisador do Programa de Mestrado e Doutorado em Administração da Universidade Municipal de São Caetano do Sul (USCS)

Manuel Antonio Meireles

Docente-pesquisador do Programa de Mestrado em Administração da Faculdade Campo Limpo Paulista (FACCAMP)

Aborda-se o potencial estratégico dos sistemas de informação voltados para redes organizacionais, com o objetivo de evidenciar a importância do domínio e discernimento dos metadados e protocolos de comunicação pelos atores da rede. A reflexão é realizada a partir da análise de dois exemplos de sistemas de informação para redes. Conclui-se que a discussão semântica das comunicações entre as organizações constituintes de redes - no âmbito da gestão da informação - é tão importante ao sucesso da cadeia quanto ao planejamento e ação cooperativa requeridas por outras dimensões da gestão.

Palavras-chaves: Protocolo de comunicação; Sistema em rede; Repositório institucional; Rastreamento de objetos. 


\title{
Extraction of larger value of collaborative information systems: importance of the semantic domain of the communication protocols by the actors
}

\begin{abstract}
The article deals with strategic potential of information systems oriented to organizational networks. The objective is to show the importance of the domain and metadata discrimination and communication protocols by network actors. The reflection is done from the analysis of two examples of network information systems. It is concluded that the semantic discussion between the represented organizational networks - in the context of information management- is as important for the success of the net as is the planning and cooperative action by other dimensions of the management.
\end{abstract}

Keywords: Communications protocol; Net System; Institutional repository; Objects tracing.

Recebido em 30.09.2009 Aceito em 05.03.2010

\section{Introdução}

Recentemente, muito se discutiu, nos meios acadêmicos e organizacionais, sobre a importância estratégica da tecnologia da informação (TI) aos negócios, discussão essa motivada pela publicação do artigo de Nicholas Carr (2003): IT doesn't matter. Carr descreveu a transformação no processo de aquisição dos recursos de TI pelas organizações, de preços elevados e restritivos às facilidades de aquisição e contratação atual. O autor afirma que, a partir do momento em que computadores e softwares passaram a estar disponíveis a todos, tornamse commodities e o seu valor estratégico desaparece. Recomenda que as empresas invistam menos em TI, não mais explorando seu potencial inovador, mas que enfatizem a segurança e a redução dos riscos de interrupção dos serviços dos seus atuais ambientes computacionais (CARR, 2003).

A vantagem competitiva sustentada apenas pela posse dos recursos de TI torna-se cada vez mais pontual, escassa e facilmente dirimida pela concorrência, bastando para tal a aquisição de recurso tecnológico idêntico ou similar. Exemplo dessa breve vantagem competitiva alcançada recentemente pela introdução de novos recursos de TI ocorreu no 
segmento das bolsas de valores, com a adoção de supercomputadores para análise e comercialização de ações em bolsas de valores (SCIARRETTA, 2009, p. b8):

Utilizando algoritmos matemáticos (seqüência de passos definidos para realizar uma tarefa), esses supercomputadores também conseguem testar o preço pelo qual um investidor tem ordem programada para vender uma ação. Por exemplo, para descobrir se um fundo de pensão tem ordem para comprar uma ação a US\$20,10, o supercomputador começa a enviar pequenas "iscas" vendendo esse papel a US\$20,01, depois US\$20,02 até obter um OK. Ao mesmo tempo, ele utiliza a mesma técnica para localizar outro investidor vendendo a mesma ação num valor próximo a esse. Se encontrar um vendedor a US\$20,08, poderá comprar todo o lote e ainda vender para o outro a US\$2,10, embolsando US\$ 0,02 por ação. E isso antes de que os dois consigam fechar negócio entre si.

Os ganhos de negócio mais imediatos e simplistas de serem alcançados pelas organizações que investem em TI é a aceleração, ou maior agilidade de suas atividades, maior facilidade de distribuição da informação entre seus membros, entre outros benefícios intrínsecos aos recursos de TI. Em analogia aos programas de qualidade, pode se afirmar que esses são os "frutos baixos", facilmente alcançados por aqueles que realizam o investimento de aquisição dos recursos de TI. Ao longo deste artigo, emprega-se o termo "automação" para referenciar a esse tipo de aplicação mais simplista e imediatista dos recursos de TI ao contexto do negócio das organizações. Em termos de implementação dos atuais sistemas de informação corporativos, parametrizáveis ou configuráveis, um exemplo dessa postura seria o que os praticantes da área denominam "baixar o software na organização", ou seja, aceitar as configurações prédefinidas (default) pela software house, sem discutir e definir, com os gestores da organização, as opções de configuração das transações de negócio mais adequadas ao contexto do negócio da empresa, ou da rede colaborativa.

Vantagens competitivas mais duradouras, portanto, de maior valor estratégico às organizações, não são mais alcançadas pela simples posse de novos recursos de TI, facilmente adquiridos pelos concorrentes, conforme salientado por Carr. Porém, isso não significa que a TI não possa colaborar estrategicamente com a organização, como muitos interpretaram a reflexão proposta por Carr. Peter Keen, por exemplo, contra argumentou à percepção da TI como recurso totalmente desprovido de valor estratégico (KEEN, 1981 apud DEVARAJ; KOHLI, 2002, p. 20, tradução nossa):

Quando todas as empresas têm, essencialmente, acesso aos mesmos recursos de tecnologia da informação, a diferença competitiva e os benefícios econômicos que as empresas possam ganhar reside no gerenciamento da TI e não nas diferenças tecnológicas.

A presente pesquisa aborda a implementação dos recursos de TI nas organizações, destacando que um sistema de informação pode proporcionar resultados totalmente distintos, de pequenos ganhos gerados 
pela postura de "automação" a proposições inovadoras que interferem diretamente na atividade principal e na capacidade competitiva da organização. Entre as muitas competências organizacionais necessárias à extração do maior valor dos sistemas de informação corporativos está o domínio de algumas questões sintáticas e semânticas associadas às estruturas de dados, em especial aos metadados relacionados aos protocolos de comunicação dos sistemas de informação voltados para ambientes de redes organizacionais. Trata-se de aspectos abstratos, de difícil percepção e de pouco domínio dos gestores, considerando-se que, muitas vezes, tais facilidades não são discutidas durante o projeto de implementação dos sistemas de informação, em especial nos projetos que adotam a política de "baixar o software", ocasionada por restrições financeiras, de prazo e/ou de conhecimento técnico.

O objetivo da pesquisa é evidenciar aos pesquisadores e praticantes da área de gestão a importância da organização em dominar e ter discernimento sobre os metadados dos sistemas de informação a fim de perceber e explorar o potencial estratégico desses recursos. A reflexão é realizada dentro do contexto de sistemas de informação corporativos voltados para redes organizacionais, ou seja, aqueles cujo valor cresce proporcionalmente ao número de organizações usuárias do sistema. Para organizações que atuam em redes, os desafios ontológicos e cognitivos atrelados aos metadados são ainda mais desafiantes e complexos, por requererem de seus atores e grupos de atores, discernimento e concordância sobre protocolo de comunicação a utilizar, valores semânticos possíveis de serem assumidos para cada um dos termos previstos no protocolo, e outros aspectos discutidos e evidenciados pela presente pesquisa.

A diversidade de atores ou de grupo de atores da rede, bem como a complementaridade das ações desses, resulta em diferentes níveis de complexidade do ambiente informacional em rede. Algumas redes implicam em maior demanda e diversidade de comunicações, o que as tornam mais desafiantes e críticas em termo de domínio de aspetos ontológicos pelos seus membros. Para retratar essa diferenciação, discutem-se questões ontológicas atreladas a dois sistemas de informação para dois ambientes de negócios que caracterizam sistemas de naturezas bem distintas:

- sistema circular entre pares: todos atores da rede desempenham funções e papéis idênticos, há uma demanda informacional comum entre todos os atores da rede e as informações geradas por uma instituição constitui-se em insumo para todas as demais instituições da rede;

- sistema linear entre díspares: cada ator ou grupo de atores da rede desempenha diferentes funções e papéis, as demandas informacionais são distintas e interdependentes em termos de cooperação para execução e gerenciamento do processo de negócio conduzido pelos atores da rede. 
Na seção três descrevem-se dois sistemas de informação voltados para redes organizacionais, um para redes circulares entre pares e outro para redes lineares entre díspares. O exemplo de sistema de informação voltado para redes circulares entre pares é o repositório institucional (RI), segundo a arquitetura Open Archives Initiative Protocol for Metadata Harvesting (OAI-PMH), no contexto das instituições de ensino e pesquisa. Os atores dessa rede realizam funções idênticas, publicam informações referentes aos resultados alcançados pelos seus pesquisadores normalmente artigos e relatórios científicos - e disponibilizam recursos para que seus pesquisadores possam ter acesso aos resultados alcançados pelos seus pares, ou seja, acesso às publicações das outras instituições de ensino e pesquisa conectadas à rede. Quanto ao sistema de informação voltado para redes lineares entre díspares o exemplo analisado é o sistema de identificação e rastreamento de produto, segundo a arquitetura ECPglobal Network. Evidencia-se a importância do fluxo colaborativo de informação entre as empresas da cadeia, necessário para que elas possam não apenas alcançar maior eficácia nas suas diversas e distintas atividades, mas propor inovações que proporcionem ganhos estratégicos aos atores da rede como um todo.

\section{Método}

Segundo Creswell (2007) há quatro abordagens científicas para alegação do conhecimento científico: a pós-positivista, a construtivista, a pragmática e a reivindicatória/participativa. No pragmatismo a atenção dos pesquisadores está "voltada para aplicações - 'o que funciona' - e soluções para os problemas" (CRESWELL, 2007, p. 29). Esta pesquisa emprega a abordagem pragmática por abordar um problema organizacional: condições necessárias à extração de maior valor dos sistemas de informação voltados para redes de organizações. Um problema que pode configurar-se, também, como uma oportunidade de âmbito estratégico. Nesse caso, o observador necessitará extrapolar os ganhos possíveis para além da mera utilização do sistema de informação no contexto da operação dos atores da rede que, em um primeiro momento, pode estar atendendo às expectativas mesmo provendo, exclusivamente, os "frutos baixos" da automação.

A pesquisa fundamentou-se, metodologicamente, numa técnica de reflexão denominada "círculo de estudos". De acordo com Bordenave e Pereira (1993) o círculo de estudos é uma técnica que se baseia na reunião de um grupo de pessoas ligadas à mesma área de atuação, com o objetivo de preparar um documento fundamentado sobre um tema de considerável significação, exigindo estudo sério, intercâmbio de idéias e deliberação. Os autores destacam que a técnica de reflexão exige o máximo de participação e integração total dos participantes.

Foi observada a forma de aplicar a técnica de reflexão descrita por Bordenave e Pereira (1993): (1) definiu-se o tema como sendo "Aspectos Semânticos dos Protocolos de Comunicação dos Sistemas de Informação 
para Redes Organizacionais para Realização do Potencial Estratégico"; (2) além dos autores foram selecionados quatro especialistas ligados à área de TI; (3) foram definidas as datas, períodos e local das reuniões; (4) foi estabelecida a pauta contendo os assuntos e a seqüência de abordagem; (5) foi estabelecida a bibliografia a ser consultada antes e durante as reuniões. Não foram indicados assessores disponíveis para consulta por se entender que os especialistas poderiam consultar seus pares para dirimir eventuais dúvidas. Os papéis de Coordenador e de Relator ficaram a cargo dos autores.

\section{Sistemas de informação voltados para redes organizacionais}

\subsection{RI segundo arquitetura OAI-PMH}

A fim de facilitar a compreensão e tornar a discussão mais próxima ao contexto da academia, optou-se por abordar a implementação de um sistema de informação voltado às redes de organizações de ensino e pesquisa. Universidades, centros de pesquisas e demais entidades tipicamente voltadas à geração do conhecimento estão sendo amplamente influenciadas pela introdução das tecnologias da informação e comunicação. O repositório institucional (RI) é resultante dessa nova realidade, sendo:

projetado para colecionar, administrar, distribuir, e conservar os ativos digitais da organização, por exemplo, as publicações acadêmicas e materiais de pesquisa dos docentes de universidades que desenvolvem pesquisas (SMITH, 2002, p.1).

Outro aspecto favorável à seleção do RI é a sua contemporaneidade: a maioria das universidades brasileiras estão para iniciar sua implementação. Para disseminação do RI entre as universidades brasileiras, o Instituto Brasileiro de Informação em Ciência e Tecnologia (IBICT) tem realizado diversas iniciativas. No final de 2008 e no primeiro trimestre de 2009 foram publicados editais direcionados às instituições públicas de ensino e pesquisa como o objetivo de prover a infra-estrutura tecnológica necessária para o desenvolvimento de seus RIs. As propostas vencedoras recebem o "kit tecnológico", em regime de comodato, composto por um computador a realizar o papel de servidor do RI, pré-formatado e configurado com (IBICT, 2009): sistema operacional, LINUX; sistema gerenciador de banco de dados, MySQL; softwares básicos, Apache e PHP; aplicativos Eprints ${ }^{1}$, DSpace ${ }^{2}$ e Sistema Eletrônico de Editoração de Revistas (SEER).

O Eprints é um software livre utilizado para implementação de repositório digital, totalmente compatível com o protocolo OAI-PMH.

2 O DSpace é um software para construção de repositórios institucionais e temáticos, desenvolvido pelo MIT em parceria com a HP. Trata-se de um software open source, 
A pesquisa desenvolve uma reflexão sobre duas posturas distintas das instituições de ensino e pesquisa com relação ao recurso sistema de informação RI: uma voltada apenas para "automação", que considera o recurso como o meio mais fácil e prático para publicação de suas pesquisas, outra como recurso inovador e estratégico, capaz de interferir positivamente na qualidade do ambiente das pesquisas científicas, não só no contexto da própria instituição, mas do macro-ambiente científico brasileiro.

Os desafios de compreensão da evolução de determinada tecnologia em termos de novas possibilidades ao negócio estão presentes não apenas no âmbito de cada organização, mas, inclusive em iniciativas de órgãos responsáveis pelo desenvolvimento tecnológico. A entidade hoje responsável pela interoperabilidade entre os diversos RIs, o Open Archives Initiative (OAI), até outubro de 1999 denominava-se Universal Preprint Service (UPS). A alteração do nome da entidade retrata o impacto da evolução tecnológica na própria missão desse órgão. O foco inicial era dispor conteúdo tradicional em papel por intermédio do ambiente virtual, aproveitando-se da abrangência da Internet para dispor em mídia digital arquivos no formato Hyper Text Markup Language (HTML), Portable Document Format (PDF) e texto do aplicativo Microsoft Word (DOC) - os conteúdos, por exemplo, de revistas acadêmicas para impressão (preprint) nas localidades de interesse. Atualmente a ênfase do OAI está na disponibilidade de metadados sobre onde encontrar determinado conteúdo, independentemente da mídia e do meio a ser escolhido pelo usuário para ter acesso ao conteúdo (HORWOOD et al., 2004).

O sistema de informação RI é um recurso fundamental para constituição dos modernos ambientes de ensino e pesquisa. Cada entidade de pesquisa deve possuir seu RI para publicação de suas pesquisas: no ambiente OAI trata-se de um computador que realiza o papel de provedor de dados (data provider). O provedor de dados armazena tanto os conteúdos (documents) quanto os metadados destes, conforme pode se observa na FIG. 1. Os metadados do conteúdo estão dispostos e organizados segundo um protocolo de comunicação, no ambiente OAI denominado de Protocol for Metadata Harvesting (PMH). A arquitetura OAI-PMH traz padronização entre todos os provedores de dados e facilita a criação de provedores de serviços (services providers). Esses possuem algoritmos ("motores de busca") programados para: pesquisa dos diferentes provedores de dados, leitura e gravação dos metadados referentes aos conteúdos armazenados nos provedores de dados. Dessa forma, os provedores de serviços armazenam apenas os metadados, ou seja, podem informar o que está disponível no macro-ambiente da pesquisa científica, bem como o meio para se acessar tais conteúdos, normalmente um endereço Internet, isto é, o código denominado tecnicamente de Uniform Resource Locator (URL).

desenvolvido em Java para plataforma Linux. No Brasil o software é distribuído pelo IBICT, que customizou a sua última versão (1.4) para a língua portuguesa. 
O protocolo de comunicação definido pela organização $\mathrm{OAI}$, O $\mathrm{PMH}$, suporta qualquer formato de metadados empregado para transmissão de dados via $\mathrm{XML}^{3}$. A OAI definiu que o formato mínimo de atributos para comunicação é o estabelecido na versão básica do padrão Dublin Core (DC), constituída por quinze termos: Title, Creator, Subject, Description, Publisher, Contributor, Date, Type, Format, Identifier, Source, Language, Relation, Coverage e Rights.

As bases de dados para pesquisa de conteúdo acadêmico desenvolvidas já no padrão OAI-PMH diferem substancialmente das desenvolvidas com tecnologias anteriores. Provedores de serviços desenvolvidos na década de 90 realizavam réplicas dos conteúdos das revistas publicadas pelas diversas instituições, estejam elas na mídia papel ou eletrônica. Nesses ambientes, ocorriam, também, retrabalhos de catalogação dos dados bibliográficos do conteúdo, atividade já realizada anteriormente pela instituição responsável pela publicação e editoração da revista científica.

A proposição do modelo tecnológico OAI-PMH é permitir que entidades possam prestar os mesmos serviços das tradicionais bases eletrônicas de conteúdos acadêmicos, porém, apenas coletando e armazenando os metadados de cada artigo e, por isso, o termo harvesters (colheitadeira) é utilizado para designar esses novos provedores de serviços que coletam apenas o metadados dos artigos, não o artigo em si. $\mathrm{O}$ arquivo do artigo no formato PDF, DOC, HTML ou outro formato, permanece armazenado, de fato, apenas no seu RI original, aquele da instituição responsável pela revista acadêmica.

A proposição atual do IBICT em colaborar com a constituição de um conjunto de RI nas instituições públicas de pesquisa, manifestada nos editais recentemente publicados, contempla a constituição de um provedor de serviços de informações referentes às pesquisas científicas brasileiras, ambiente denominado de "Portal de Repositórios e Periódicos de Acesso Livre" ou simplesmente OASIS (acrônimo do nome do portal traduzido para 0 inglês). As instituições que se candidatam ao recebimento do "kit tecnológico" se comprometem a colaborar com a constituição de tal ambiente, conforme instruções contidas no próprio edital.

3 XML (eXtensible Markup Language) é um formato padrão, amplamente aceito, para a criação de documentos com dados organizados de forma hierárquica. Apresenta portabilidade, ou seja, uma aplicação pode escrever em um arquivo XML que será lida por outra, independente de sua plataforma de harware e software. 


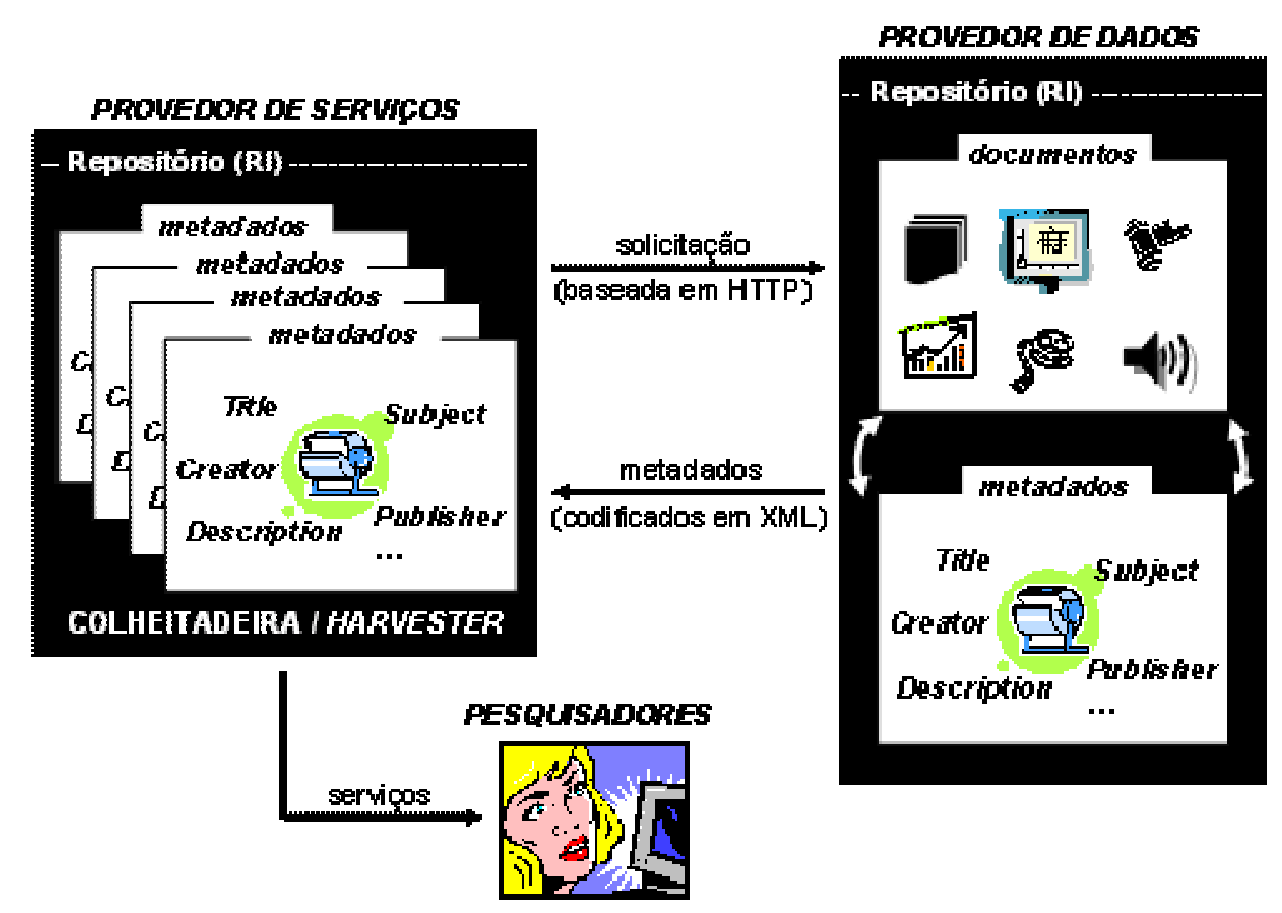

FIGURA 1 - Macro-arquitetura funcional do OAI-PMH

Fonte: Adaptado de OPEN ARCHIVES FORUM (2009).

\subsection{Identificação e rastreamento de produto segundo arquitetura EPCglobal Network}

Tecnologias têm sido empregadas para identificar e rastrear entidades físicas nos ambientes corporativos: código de barras, sinais de rádio-freqüência, leitura de características biométricas e cartões inteligentes são alguns exemplos. Para embasar a discussão da importância do domínio de metadados dos softwares corporativos aplicados a sistemas lineares entre díspares, apresenta-se nesta subseção a solução de identificação e rastreamento de produto dentro da cadeia produtiva estendida.

Nos últimos anos, presenciou-se o crescimento da adoção da tecnologia de auto-identificação de objetos físicos via ondas de rádio, denominada de RFID (Radio Frequency IDentification). A tecnologia RFID foi desenvolvida pelo Centro de Auto-identificação (Auto-ID Center) do Instituto de Tecnologia de Massachusettes (MIT), atualmente é apoiada e disseminada pelo EPCglobal Network, organização sem fins lucrativos, responsável pela padronização e disseminação do Código Eletrônico do Produto ou Eletronic Product Code (EPC). Com a utilização do EPC ao longo de toda cadeia estendida, o EPCglobal Network objetiva tornar as cadeias mais eficazes, considerando as melhorias proporcionadas ao ambiente informacional da cadeia (ANGELES, 2005).

A macro-arquitetura funcional da solução de identificação e rastreamento de produto desenvolvida pelo EPCglobal Network está descrita na FIG. 2. Conjuntos de produtos, produtos isoladamente ou 
partes do produto, podem receber um código identificador, ou simplesmente um EPC, digitalmente codificado em um artefato denominado tag, composto por um micro-processador e uma antena transmissora. As entidades físicas que possuem tags são identificadas pelos dispositivos de leitura distribuídos ao longo das empresas constituintes da cadeia estendida. Cada ator constituinte da cadeia habilitada pelo EPCglobal Network possui um software denominado EPC Discovery Service (EPC-DS), também conhecido como software Savant. Este recebe o código EPC lido pelos dispositivos de leituras e envia uma solicitação de informação ao sistema Object Naming Service (ONS) para encontrar o endereço lógico daquele produto: um endereço Internet (número IP). De posse do endereço lógico do produto em processamento/manuseio, o software EPC-DS solicita informações à empresa da cadeia responsável pelo produto. As empresas constituintes da cadeia possuem um EPC Information Service (EPC-IS) para cada um de seus produtos. O EPC-IS envia dados de seu produto ao EPC-DS da empresa solicitante, via linguagem PML (Physical Mark-up Language) que é específica para descrição de objetos físicos via Internet e apropriada para que sistemas de monitoramento e controle possam agir sobre ambientes físicos.

De posse das informações do produto que está em processamento/manuseio, entregues pelo EPC-DS, a empresa pode tomar decisões mais eficazes, bem como supervisionar e executar com mais eficácia as atividades em execução. Seguem alguns exemplos da importância da disponibilidade de dados sobre o produto no momento de seu processamento/manuseio:

1. Consultar o cadastro do produto (EPC-IS) na organização produtora, a fim de direcionar os trabalhos da empresa responsável pelo centro de distribuição com relação à temperatura ideal para estocagem do produto, evitando equívocos de estocagem de produtos em câmaras frigoríficas inadequadas;

2. Consultar o cadastro do produto (EPC-IS) na organização produtora, a fim de direcionar os trabalhos da empresa transportadora, averiguando, por exemplo, se é possível empilhar o produto, evitando transportes inapropriados;

3. Consultar o cadastro do produto (EPC-IS) na organização produtora, a fim de direcionar os trabalhos da empresa de assistência técnica, averiguando os prazos e serviços a serem realizados para cada ciclo de manutenção previsto para o produto.

As informações do produto, disponível no EPC-IS da empresa responsável pelo mesmo, podem agregar valor às diversas atividades executadas pelas empresas da cadeia que manipulam/processam 0 produto ao longo de toda a cadeia colaborativa. 


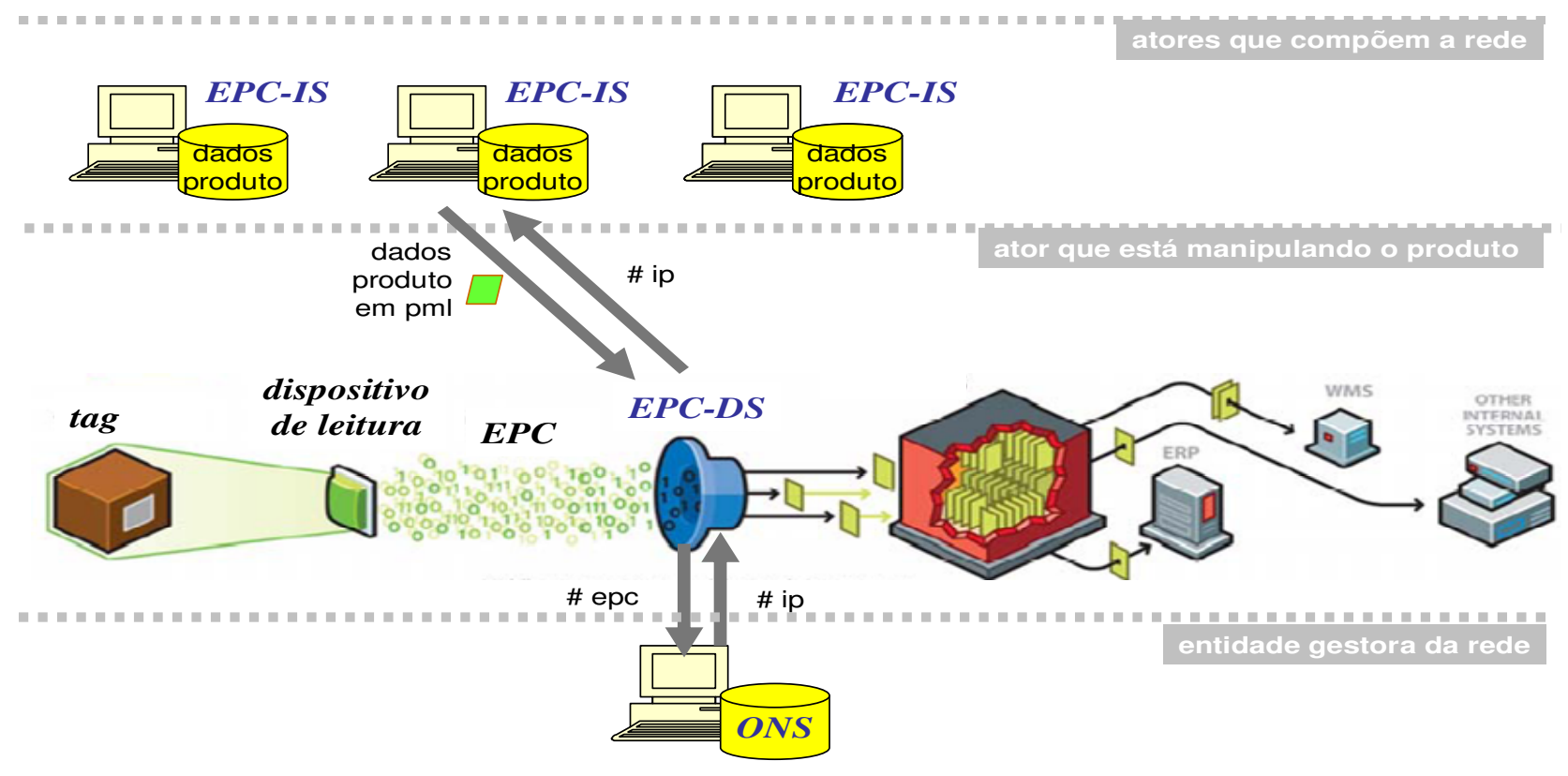

FIGURA 2 - Macro-arquitetura funcional do EPCglobal Network

Fonte: Dados da pesquisa.

\section{Obtenção de maior valor estratégico de sistemas de informação voltados para redes a partir do discernimento de seus aspectos semânticos}

Na segunda parte desta seção discutem-se diferentes percepções de aplicação dos recursos de tecnologia da informação em sistemas lineares entre díspares, mais especificamente da aplicação da tecnologia de RFID para identificação e rastreamento de produto. Discute-se desde a percepção simplista de automação, onde o RFID é visto como tecnologia alternativa ao código de barra, até a percepção mais ampla e de vanguarda que emprega a tecnologia RFID como elemento integrador das operações entre os diversos membros da cadeia. Na primeira parte desta seção são desenvolvidas análises de aplicações não tradicionais do recurso RI, ou seja, aplicações distintas da visão tradicional de "automação" da biblioteca ou dos acervos físicos em papel para mídia digital. Discute-se o RI como instrumento não apenas voltado para organização, administração, distribuição e conservação de publicações resultantes de pesquisas e materiais didáticos da instituição de ensino e pesquisa, mas, principalmente, como meio capaz de contribuir com o incremento de qualidade da pesquisa científica desenvolvida e publicada pela instituição. A discussão da percepção de ganhos estratégicos ocorre também em termos de rede, do ambiente colaborativo constituído pelas diversas instituições de ensino e pesquisa que adotem o RI com um mesmo padrão de protocolo de comunicação. Quanto mais instituições disponibilizarem o RI, maior potencialidade terá o ambiente de rede (ou "constelação") de 
RIs em proporcionar ganhos efetivos aos participantes da rede, por exemplo, pelo acesso compartilhado de artigos científicos publicados.

\subsection{Utilização estratégica do sistema RI a partir do domínio sintático e semântico de suas estruturas de dados}

Para incremento da qualidade da pesquisa científica, acredita-se nas potencialidades do RI em vincular aos artigos científicos (ou outras formas de divulgação da pesquisa científica, como relatórios e working papers) às diversas evidências obtidas que consubstanciam as análises realizadas. Como incremento do ambiente em rede da pesquisa científica, mais específicamente da eficácia dos acervos públicos (sem restrições de acesso) das pesquisas científicas brasileiras, destaca-se a disponibilidade de facilidades da arquitetura da rede ("constelação") de RI em averiguar a unicidade da publicação dos resultados da pesquisa, não quanto ao seu armazenamento físico ou lógico (o que seria conservação/preservação da informação), mas do ponto de vista de consolidar, de centralizar os resultados da pesquisa em apenas um ponto, por exemplo, em um artigo ou relatório.

\subsubsection{Publicação de evidências: acurácia e credibilidade da informação científica}

A primeira qualidade intrínseca do RI é a sua capacidade de prover facilidades para armazenamento e recuperação de informações. A disponibilidade do RI aos pesquisadores, de forma planejada e estruturada, configura-se como importante recurso no sentido de prover facilidades técnicas para publicação de informações pertinentes as suas pesquisas, em especial, das evidências utilizadas em suas análises. Entre elas enquadram-se: transcrições de entrevistas realizadas pelos pesquisadores, filmagens em formato digital, registro sonoro (de uma entrevista, por exemplo), tabelas com apontamentos de dados levantados e a descrição detalhada das fórmulas aplicadas, fotos de objetos de interesse da pesquisa, entre outras formas possíveis de registro de evidências relacionadas às pesquisas.

Entre os metadados do protocolo de comunicação padrão Dublin Core Metadata Initiative (DCMI), há um termo (ou atributo) denominado type que tem a função de especificar o tipo do conteúdo informacional armazenado no RI. A organização DCMI mantém e publica a lista dos tipos possíveis de serem assinalados para cada conteúdo publicado no RI, bem como do código correspondente a ser registrado na base de dados. $\mathrm{Na}$ TAB. 1 é apresentada a lista dos tipos previstos pelo DCMI.

O padrão DCMI estabelece a associação lógica entre a pesquisa publicada, por exemplo, um artigo publicado no RI, e as suas evidências, por intermédio de dois termos constituintes dos seus metadados: hasPart e isPartOf. O primeiro termo - hasPart - descreve os recursos que 
constituem parte integrante da instância em questão, ou seja, da entidade da qual os metadados dizem respeito; o segundo termo - isPartof -, opostamente, indica as entidades que são constituídas, compostas pelo recurso em questão.

\section{TABELA 1 Especificação de tipo do conteúdo armazenado no RI, segundo padrão DCMI}

\begin{tabular}{|c|c|}
\hline $\begin{array}{l}\text { Valores possíveis } \\
\text { de serem atribuídos } \\
\text { ao termo Type }\end{array}$ & Descrição e Exemplos \\
\hline Collection & $\begin{array}{l}\text { Uma agregação de recursos. Uma coleção é descrita com um grupo; suas } \\
\text { partes também podem ser descritas separadamente. }\end{array}$ \\
\hline Dataset & $\begin{array}{l}\text { Dados codificados em uma estrutura definida. Exemplos incluem listas, tabelas } \\
\text { e bases de dados. Um dataset pode ser útil para ser diretamente processado } \\
\text { por um computador. }\end{array}$ \\
\hline Event & $\begin{array}{l}\text { Uma ocorrência não persistente, baseada em tempo. Metadados de evento } \\
\text { provê informações descritivas que é a base para descoberta do propósito, } \\
\text { localização, duração e agentes responsáveis pelo evento. Exemplos incluem } \\
\text { uma exibição, um webcast, uma conferência, um workshop, um open day, uma } \\
\text { performance, uma batalha, um julgamento, um casamento, um chá, uma } \\
\text { conflagração. }\end{array}$ \\
\hline Image & $\begin{array}{l}\text { Uma representação visual diferente de texto. Exemplos incluem imagens e } \\
\text { fotografias de objetos físicos, pinturas, impressos, desenhos, outras imagens e } \\
\text { gráficos, animações e desenhos em movimento, filmes, diagramas, mapas e } \\
\text { notações musicais. Observar que imagem pode incluir representações físicas e } \\
\text { eletrônicas. }\end{array}$ \\
\hline InteractiveResource & $\begin{array}{l}\text { Um recurso requerendo interação do usuário para ser entendido, processado, } \\
\text { ou experimentado. Exemplos incluem formulários de páginas da Internet, } \\
\text { applets, objetos de aprendizagem multimídia, serviços de bate-papo, ou } \\
\text { ambientes de realidade virtual. }\end{array}$ \\
\hline Movinglmage & $\begin{array}{l}\text { Uma série de representações visuais transmitindo a impressão de movimento } \\
\text { quando apresentadas sucessivamente. Exemplos incluem animações, filmes, } \\
\text { programas de televisão, vídeos, zoetropes, ou produtos visuais gerados a partir } \\
\text { de um simulador. Instâncias desse tipo (Movinglmage) também devem ser } \\
\text { descritas como instâncias de algo mais amplo, por intermédio do termo Image. }\end{array}$ \\
\hline PhysicalObject & $\begin{array}{l}\text { Um inanimado, tri-dimensional objeto ou substância. Observe que } \\
\text { representações digitais, ou substitutos, para esses objetos devem usar imagem } \\
\text { (termo Image), texto (termo Text) ou um dos outros tipos. }\end{array}$ \\
\hline Service & $\begin{array}{l}\text { Um sistema que provê uma ou mais funções. Exemplos incluem um serviço de } \\
\text { fotocópia, um serviço bancário, um serviço de autenticação, empréstimos entre } \\
\text { bibliotecas, um protocolo Z39.50 ou um serviço via web. }\end{array}$ \\
\hline Software & $\begin{array}{l}\text { Um programa de computador, seja sua fonte ou versão compilada. Exemplos } \\
\text { incluem uma fonte de programa na linguagem C, O MS-Windows.exe } \\
\text { executável, ou Perl script. }\end{array}$ \\
\hline Sound & $\begin{array}{l}\text { Um recurso desenvolvido com objetivo principal de ser ouvido. Exemplos } \\
\text { incluem arquivos no formato para o playback de uma música, um disco } \\
\text { compacto com áudio, e registros de discurso ou sons. }\end{array}$ \\
\hline StillImage & $\begin{array}{l}\text { Uma representação visual estática. Exemplos incluem pinturas, desenhos, } \\
\text { gráficos, plantas e mapas. As melhores práticas recomendam assinalar, utilizar } \\
\text { o termo texto (Text) para imagens de materiais textuais. Instâncias desse tipo } \\
\text { (StillImage) também devem ser descritas como instâncias de algo mais amplo, } \\
\text { por intermédio do termo Image. }\end{array}$ \\
\hline Text & $\begin{array}{l}\text { Um recurso consistindo primariamente de palavras para leitura. Exemplos } \\
\text { incluem livros, cartas, poemas, jornais, artigos, arquivos e lista de endereços. } \\
\text { Observe que facsimiles ou imagens de textos continuam sendo texto (termo } \\
\text { Text). }\end{array}$ \\
\hline
\end{tabular}

Fonte: Adaptado de DUBLIN CORE METADATA INITIATIVE (2009). 
Desta forma, um RI que utilize o padrão DCMI pode acatar e identificar novos conteúdos bem como suas partes constituintes. Por exemplo, ao se disponibilizar um relatório ou artigo de uma pesquisa, pode-se vincular um arquivo do tipo texto contendo a transcrição das falas, assim como um arquivo de som com a gravação das entrevistas. 0 registro lógico desta estrutura todo-parte, bem como de pesquisa com relação a essa informação, só é possível de ser criada devido ao emprego dos dois termos acima descritos.

Os termos hasPart e isPartOf não são de uso obrigatório no padrão DCMI, pois nem toda entidade representada no RI precisa ser composta por partes, assim como não necessita compor outras entidades mais abrangentes. Por serem termos de preenchimento opcional, dentre os vários metadados do padrão DCMI, acaba por reduzir a percepção de importância e uso desses termos em implementações de RIs, caracterizando-os como algo desnecessário para aqueles que desejam apenas colocar o RI em funcionamento da forma mais trivial possível: a "automação". Como no ambiente dos repositórios físicos predomina a inexistência de associações entre as formas de expressões da pesquisa (relatórios e artigos) e suas evidências, repetem-se no ambiente virtual as mesmas limitações do mundo físico, porém, de forma mais rápida e mais segura, ou seja, obtêm-se apenas os "frutos baixos" da automação.

O pouco discernimento das potencialidades do RI conduz os gestores responsáveis pela sua adoção e implementação, a compreendê-lo de forma simplista, como uma ferramenta de T.I. Nessa situação, o RI é entendido como, por exemplo, uma biblioteca eletrônica ou ambiente para revistas eletrônicas. O recurso entendido como ferramenta de publicação não aprimora ou auxilia na qualidade do que se publica, mas trabalha ganhos de percepção em relação às vantagens do meio digital em relação à mídia física (papel): mais rápido acesso, disponível em qualquer localidade que tenha acesso Internet, controle de acessos digital mais seguro, entre outros. Por outro lado, a compreensão das potencialidades do RI habilita gestores a percebê-lo não como ferramenta, mas como instrumento que pode colaborar efetivamente com a atividade fim, com a missão e objetivos da sua instituição, por exemplo, como colaborar com a qualidade das pesquisas de sua instituição.

Dispor de infraestrutura tecnológica que auxilie os pesquisadores da instituição a publicarem adequadamente as evidências de suas pesquisas proporciona diversos benefícios. No âmbito interno, auxilia na fixação da prática, do comportamento de seus pesquisadores em publicar as evidências de suas pesquisas, ao demonstrar atitudes concretas e coerentes entre normas, recomendações e recursos disponíveis. No âmbito externo, aprimora a qualidade das informações científicas publicadas pela instituição, por agregar e contribuir diretamente com pelo menos duas das dimensões da qualidade da informação: acurácia e credibilidade (DE SORDI, 2008).

Pesquisas com evidências publicadas apresentam maior percepção de qualidade e, conseqüentemente, maior potencial de acesso e citação. 
Bases eletrônicas de periódicos científicos - como ProQuest, EBSCO, JSTOR - permitem ao usuário definir um conjunto de critérios para pesquisa a se realizar. Publicações com artigos completos são muito mais atrativos e acessados do que publicações que apresentam apenas resumos. Nessas bases eletrônicas o pesquisador pode optar por pesquisar "Apenas documentos com texto completo". A partir desse exemplo, vislumbra-se o potencial de agregação de valor do RI aos seus usuários caso houvesse opções associadas à existência de evidências atreladas aos documentos publicados. Desde a opção simplista de listar "Apenas documentos com evidências associadas" até a geração de diagramas de rede, cujo documento é a entidade central do gráfico e seus satélites são as evidências organizadas, por exemplo, por mídias empregadas (.PDF, .DOC, .XLS, .MPG, .MP3, .WAV, .CAD) ${ }^{4}$ ou tipos de evidências segundo o método científico (entrevistas, filmagens, planilhas de cálculos, transcrição de entrevistas, fotos).

Apesar dos recursos e facilidades do ambiente OAI-PMH e DCMI para associação de evidências ao artigo ou ao relatório científico, a grande maioria dos RI ainda não utilizam-se de tais facilidades. A compreensão da estrutura sintática e semântica das estruturas de dados e protocolos de sistemas de informação corporativos é fundamental para alteração de perspectivas modestas, de apenas "baixar o software", para proposições de maior valor agregado que possam utilizar-se de todo potencial estratégico desses recursos.

O estudo e compreensão da estrutura de dados e dos protocolos de comunicação de novos softwares corporativos são fundamentais para identificação das possibilidades desses dentro do contexto da organização: se será percebido como uma ferramenta ou se trará uma alteração de determinada realidade importante ao negócio e, portanto, compreendido como uma solução de negócio. A despeito dos slogans de marketing das empresas de consultoria e de softwares empresariais, muitos recursos de sistemas corporativos com potencial para geração de resultados estratégicos ao negócio, por incorporarem excelente capital intelectual de anos de desenvolvimento, em diferentes organizações, acabam reduzidos a ferramentas com resultados restritos aos da automação.

O exemplo do RI é oportuno e adequado à discussão acadêmica do potencial estratégico de novos recursos de TI. Oportuno devido ao investimento atual do governo brasileiro em dispor as tecnologias necessárias à implementação do RI nas instituições públicas de ensino e pesquisa, adequado por se tratar de um recurso aplicado a uma realidade do contexto dos pesquisadores, cujos benefícios possíveis, tanto da mera automação quanto em termos de solução para o negócio, são mais

\footnotetext{
XLS é a extensão de arquivo utilizada para identificar planilha de dados do aplicativo Microsoft Excel; MPG é a extensão para vídeo digital padronizado pelo Moving Picture Experts Group (MPEG) que abrange os formatos MPEG-1 ou MPEG-2 para compressão de áudio e vídeo para filmes distribuídos na Internet; WAV é abreviação de Waveform Audio File Format, arquivo de áudio para Windows; CAD é a extensão de arquivo gerado pelo software Autodesk que é um aplicativo de projeto auxiliado por computador.
} 
facilmente percebidos e compreendidos, considerando-se tratar de um recurso de uso cotidiano dos pesquisadores.

\subsubsection{Provedores de serviços de informação científica: ineditismo da informa científica}

A infra-estrutura tecnológica dos RI que está sendo disponibilizada com o apoio do IBICT contempla um software aplicativo específico para construção e gestão de publicação periódica eletrônica: o "Sistema Eletrônico de Editoração de Revistas" (SEER). Esse sistema é resultante do trabalho do IBICT de tradução para o português e customização às necessidades brasileiras do software Open Journal Systems, desenvolvido pela Universidade de British Columbia do Canadá e que utiliza os padrões de interoperabilidade segundo o modelo OAI-PMH (MORENO; LEITE; ARELLANO, 2006).

A existência da informação referente às pesquisas, em especial na forma de artigo, é preservada na sua localidade, ou seja, no RI tecnicamente conhecido como provedor de dados (data provider) - no qual o conteúdo está armazenado, geralmente o RI da instituição responsável pela editoração da revista. Não há necessidades de réplica do conteúdo como ocorre, por exemplo, em tradicionais bases eletrônicas de conteúdos acadêmicos desenvolvidas com as tecnologias disponíveis na década de 90. Nesses ambientes, o arquivo de cada artigo é copiado do ambiente da revista (data provider) para dentro de cada um dos meios de armazenamento do provedor de serviços de busca (services provider), para posteriormente ser catalogado e indexado. Ou seja: repetem-se todas as etapas previamente já realizadas no ambiente da revista que o publicou.

Para fins de análise da dimensão ineditismo da informação (DE SORDI, 2008), no caso de artigos derivados das pesquisas científicas, editores de revistas científicas são beneficiários diretos das facilidades da arquitetura de "constelação" de RI que apresentam padronização tecnológica quanto as suas estruturas de dados e protocolos de comunicação. Com o padrão OAI-PMH, assegura-se a interoperabilidade e permitem-se facilidades, para pesquisa, aos metadados dos artigos publicados pelas revistas acadêmicas hospedadas nos diferentes RI que adotam o mesmo padrão. Isso permite aos editores de revistas e demais envolvidos com questões de qualidade das pesquisas, averiguarem a existência de artigos idênticos ou muito similares, que caracterizem evidências da falta do atributo ineditismo da pesquisa científica. Tal fato ocorre em função do recorte de uma mesma pesquisa em vários artigos, situação denominada por Castiel e Sanz-Valero (2007) como "ciência salame". Nesse aspecto, cada novo RI torna-se um importante instrumento de controle e observância ao atributo ineditismo requerido à pesquisa científica de qualidade.

Obviamente a mesma infraestrutura tecnológica de provedores de serviços de busca das informações científicas (services provider), que 
auxilia os editores na avaliação da dimensão ineditismo/raridade do artigo ou informação científica, colabora, também, com os pesquisadores no desenvolvimento de suas pesquisas que, costumeiramente, demandam pesquisas às publicações anteriores.

O aspecto mais interessante deste tópico é a padronização e a adoção do protocolo de comunicação por todos os interessados: os editores de revistas científicas e demais entidades interessadas na qualidade das pesquisas científicas. Na comparação entre soluções similares para busca de informações científicas (services provider) de gerações tecnológicas distintas, há um esforço extremamente reduzido das mais recentes em decorrência da adoção do modelo OAI-PMH.

Soluções em rede para publicação e divulgação de pesquisas científicas caracterizam-se consideradas como sistema circular entre pares. Entre pares por abranger predominantemente pesquisadores, circular por caracterizar um sistema fechado de interesses mútuos de publicação e acesso de pesquisas, ou seja, as instituições tanto desejam divulgar suas pesquisas como também acessar e conhecer as pesquisas das demais instituições. Questões ontológicas para sistemas circulares entre pares podem ser facilmente dirimidas se 0 foco for apenas automação, devido a todos realizarem as mesmas atividades. No caso em questão da constelação de RI, há um facilitador a mais, pois a estrutura de dados bibliográfica é bem estável e difundida entre todos os atores, bem como os valores semânticos possíveis de serem assumidos por cada um dos atributos dessa estrutura. Porém, como se observou, caso se pretenda alcançar algo a mais além dos ganhos diretos da automação, as questões e aspectos ontológicos da solução tornam-se mais desafiadores. Por exemplo, caso se pretenda incentivar a publicação e pesquisa baseada em evidências disponíveis, há a necessidade de se incluir novos atributos na estrutura de dados, como os termos hasPart e isPartOf do padrão DCMI.

\subsection{Utilização estratégica do sistema de identificação e rastreamento de produto a partir do domínio sintático e semântico de suas estruturas de dados}

Estruturas de dados (sintaxe) e valores possíveis de serem atribuídos a cada um de seus campos (semântica) são mais facilmente discutidos e estabelecidos em cadeias caracterizadas como sistemas circulares entre pares. Exemplo análogo à rede de RIs constituída pelas instituições de ensino e pesquisa que adotam o padrão OAI-PMH é o padrão para transações eletrônicas entre bancos e destes para com seus clientes, definido pela Centro Nacional de Automação Bancária (CNAB). Outro exemplo são os pools de empresas de um mesmo segmento que se dedicam à padronização de estrutura sintática e semântica que permite trocas de dados necessários para disponibilização de soluções colaborativas para compra integrada de insumos produtivos (e-sourcing) e de materiais indiretos (e-procurement). 
Porém, nem toda solução de sistema de informação colaborativa aplica-se a redes circulares entre pares. Muitas são voltadas para soluções lineares, constituídas por grupos de atores que desempenha diferentes papéis e atividades dentro da cadeia, com propósitos e demandas informacionais bastante distintas. Nessa situação, em um primeiro momento, não se evidência facilmente interesses e aspectos informacionais comuns entre os atores da rede, que os motivem a discutir e trabalhar conjuntamente questões ontológicas pertinentes às estruturas sintáticas e semânticas necessárias à eficácia comunicacional entre os atores da rede. Soluções de sistemas de informação para identificação e rastreamento de produto, empregados para gestão da cadeia de fornecedores (Supply Chain Management ou SCM) e para o desenvolvimento colaborativo de produto (Product Lifecycle Management ou PLM ${ }^{5}$ ), são exemplos típicos de tal desafio.

Soluções para identificação e rastreamento de produto, como as desenvolvidas pela EPCglobal Network, utilizam o serviço de informação do produto (EPC-IS) para agregar valor durante todo o ciclo de vida do produto sendo de extrema importância tanto para soluções de SCM quanto de PLM. As informações do produto, disponíveis no EPC-IS de determinada empresa responsável pelo mesmo, podem agregar valor às diversas empresas da cadeia colaborativa, tanto as posicionadas a montante ou a jusante de suas atividades em termos de fluxos de trabalhos relativos ao processo de negócio desenvolvido pela cadeia colaborativa.

Redes que congregam organizações experientes na discussão de aspectos ontológicos para soluções de sistemas de informação colaborativos, beneficiam-se da experiência e do conhecimento prévio dessas em lidar com estruturas de dados e protocolos de comunicação. 0 correto discernimento do valor semântico dos dados disponíveis nos diversos atores da cadeia pode ser utilizado, por esses mesmos atores, como informação relevante aos diferentes pontos de tomada de decisão ao longo do processo de negócio executado pela cadeia colaborativa. Tais benefícios podem ser obtidos, mesmo em ambientes caracterizados como sistemas lineares entre díspares, que apresentam maiores desafios informacionais. No exemplo apresentado na seção de dois, de identificação e rastreamento de produto segundo arquitetura EPCglobal Network, evidenciou-se a oportunidade de ganhos aos diversos atores da cadeia a partir do melhor compartilhamento das informações entre os membros constituintes da cadeia.

Uma percepção restrita aos aspectos tecnológicos, dentro de uma abordagem de automação, pode levar a cadeia colaborativa a compreender a solução proposta pelo EPCglobal Network como uma mera troca de tecnologia, com restrição de ganhos para todos os seus membros. É muito comum a implementação da tecnologia RFID apenas como meio de substituição e descarte da tecnologia de código de barra

5 PLM é o processo de gestão do ciclo de vida de um produto e inclui a concepção, fabricação, utilização e descarte. 
por recursos que utilizam rádio-freqüência (tag, beacon, transponder). Nesta perspectiva mais simplista de renovação tecnológica, os principais objetivos a serem alcançados com a adoção do RFID são: a) facilidade de manuseio de caixas, ou seja, desobrigação de ter o código de barra e, conseqüentemente, um determinado lado da caixa direcionado para o dispositivo de leitura, ou seja, não há mais lado certo para disposição de um pacote; e b) contagem eletrônica sem necessidade de ação física como no código de barra, ou seja, não há mais a necessidade de levar o dispositivo de leitura próximo a cada um dos objetos a serem identificados, no RFID o dispositivo de leitura capta a distância o sinal de rádio emitido pelos tags.

Da mesma forma que na introdução da rede de RI, pode-se obter resultados diversos, desde os ganhos de aprimoramento diretos obtidos pela simples substituição da mídia física (papel) pela virtual (digital), até inovações significativas em termos de qualidade do ambiente de pesquisa, na introdução da tecnologia de identificação de objetos por rádio freqüência (RFID), também, pode-se se obter apenas aprimoramentos em termos de facilidade no manuseio e registro de produtos até mudanças e ganhos de maior porte, por exemplo, de automação e supervisão dos pontos de tomada de decisão ao longo de toda a cadeia produtiva.

\section{Conclusões}

As reflexões desenvolvidas a partir dos dois casos analisados, sistema de RI integrados segundo a arquitetura OAI-PMH e identificação e rastreamento de produto segundo a arquitetura EPCglobal Network, evidenciaram posturas organizacionais bastante distintas quanto ao discernimento e uso dos sistemas de informação voltados para redes organizacionais. Apresentou-se desde a postura de ganhos restritos à automação, decorrente da mera substituição tecnológica, até a perspectiva inovadora com interferência positiva e direta em processos, produtos e serviços das empresas constituintes da rede colaborativa.

Com os exemplos e análises desenvolvidas, evidenciou-se a importância dos profissionais de negócio em terem o discernimento das estruturas de dados empregadas pelas soluções colaborativas em rede, tanto as utilizadas para armazenamento quanto para transmissão de dados, a fim de explorar com profundidade e extensão os diversos recursos disponíveis nesses sistemas. De forma indutiva, a partir do domínio da sintaxe e semântica dessas estruturas de dados, pode-se propor a utilização de elementos e facilidades destas, na forma de insights inovativos, introduzidos por intermédio do próprio sistema de informação em rede que está apto a trabalhar com tais estruturas de dados.

Há um cenário favorável, em termos de ambiente de negócios, para incremento da percepção de valor e emprego estratégico das estruturas de dados disponibilizadas pelos sistemas de informação corporativos. Análise do histórico recente e de projeções a respeito da forma como as empresas se organizam e executam seus trabalhos, indicam tendências de 
crescimento do trabalho intensivo e colaborativo (BELL; KOZLOWSKI, 2002), bem como do acréscimo da quantidade de softwares utilizados para operação e gerenciamentos dessas empresas (RUH; MAGINNIS; BROWN, 2001). Maior interatividade entre empresas e maior disponibilidade e utilização de estruturas de dados por essas, constituem um ambiente desafiador em termos de trabalho cognitivo, em especial, ao que se refere às questões ontológicas associadas ao domínio das estruturas sintáticas e semânticas dos diversos softwares corporativos envoltos na operação e gerenciamento dos processos colaborativos constituídos e operados por essas empresas.

A demanda e os ganhos estratégicos relativos ao consenso e ao domínio de aspectos ontológicos das estruturas de dados são mais expressivos em ambientes colaborativos, constituídos por organizações com atividades fins distintas e integradas em termos de fluxo de trabalho - sistema linear entre díspares. Nesses ambientes, cada ator ou grupo de atores desempenha um papel específico dentro da rede e apresenta demandas informacionais distintas, porém interdependentes. A concentração de cada ator apenas em suas demandas informacionais deve ser evitada pela entidade gestora da rede, que deve buscar a equalização dessas demandas a partir de uma visão integradora, capaz de criar uma comunicação eficaz entre os atores da rede. A eficácia dessa comunicação passa pela discussão e consenso de questões ontológicas, em especial dos valores semânticos compartilhados por todos os atores da rede.

A gestão da informação entre organizações constituintes de redes colaborativas, com destaque para discussão semântica de suas comunicações, é tão importante ao sucesso da cadeia quanto ao planejamento e ação cooperativa requerida para outras dimensões e recursos da gestão empresarial em redes: desenvolvimento integrado do produto, desenvolvimento integrado da produção, desenvolvimento integrado de campanhas e de comunicação ao mercado, entre outras. Algumas cadeias colaborativas chegam a constituir novas empresas a fim de servir como elemento integrador dos diversos atores da cadeia, ou seja, promover a comunicação eficaz entre os diversos atores da cadeia.

Cada vez mais as estruturas de dados dos sistemas de informação corporativos abrangem representações de entidades do ambiente negócio que vão além dos cadastros (produtos, funcionários, clientes, materiais, ativos fixos) e das transações de negócios entre estes (venda, compra, contratação, utilização). Passaram a registrar, também, valores cognitivos pertinentes à estruturação e relacionamento entre entidades do negócio, bem como informações pertinentes a regras de operação e gerenciamento dos processos de negócio. Até então, tal conhecimento estava presente e registrado na mente dos profissionais executores (conhecimento tácito) e/ou nas linhas de código dos softwares (conhecimento explícito). Explicitar esse conhecimento por meio de estruturas de dados de softwares auxilia a tornar a operação e gestão dos processos colaborativos entre organizações menos dependente dos profissionais de informática, em termos de não demandar alterações de linhas de código de 
programas, bem como da memória e tempo escasso dos gestores de negócios. A mesma estrutura de dados que reduz limitações e barreiras operacionais da cadeia, pode auxiliar na obtenção de ganhos estratégicos para os membros da cadeia como um todo.

Como proposição para continuidade da presente pesquisa sugere-se analisar $o$ emprego e destinação dada aos RI, em termos de funcionalidades e serviços de softwares disponibilizados aos usuários, para cada um dos novos ambientes constituídos a partir dos "kits tecnológicos" fornecidos pelo IBICT. Quantos desses ambientes foram além da automação, da substituição do papel pelo digital, e incorporaram algum valor estratégico ao negócio, por exemplo, em termos de melhoria da qualidade das suas pesquisas científicas pela publicação das evidências das pesquisas? Os nomes das vinte e cinco instituições cujas propostas estavam em conformidade com o edital do IBICT, que foram contempladas com o fornecimento do "kit tecnológico" foi publicada na Internet pelo próprio IBICT (2010). Pesquisa similar pode ser realizada a partir da lista de instituições usuárias do software DSpace (2009).

\section{Referências}

ANGELES, R. RFID technologies: supply-chain applications and implementation issues. Information Systems Management, Boston, v. 22, n.1, p. 51-65, 2005.

BELL, B.; KOZLOWSKI, S. J. A typology of virtual teams: implications for effective leadership. Group \& Organization Management, Thousand Oaks; v. 27, n. 1, p. 14-49, 2002.

BORDENAVE, J. D.; PEREIRA, A. M. Estratégias de ensino-aprendizagem. Petrópolis: Vozes, 1993.

CARR, N. G. IT doesn't matter. Harvard Business Review, Boston, v. 81, n. 5, p. 41-49, May 2003.

CASTIEL, L. D.; SANZ-VALERO, J. Entre fetichismo e sobrevivência: o artigo científico é uma mercadoria acadêmica? Cad. Saúde Pública, Rio de Janeiro, v. 23, n. 12, p. 3041-3050, 2007.

CRESWELL, J. Projeto de Pesquisa: métodos qualitativo, quantitativo e misto. 2ed. Porto Alegre: Bookman, 2007.

DE SORDI, J. O. Administração da informação: Fundamentos e práticas para uma nova gestão do conhecimento. São Paulo: Saraiva, 2008.

DEVARAJ, S.; KOHLI, R. The IT payoff: measuring the business value of information technology investments. New Jersey: Prentice Hall, 2002.

DSPACE. Who's using DSpace: repository list. Disponível em: $<$ http://www.dspace.org/whos-using-dspace/Repository-List.html $>$. Acesso em: 1 ago 2009. 
DUBLIN CORE METADATA INITIATIVE. DCMI type vocabulary. Disponível em: <http://dublincore.org/documents/dcmi-type-vocabulary/>. Acesso em: 12 ago. 2009.

HORWOOD, L. et al. OAI compliant institutional repositories and the role of library staff. Library Management, Bradford, v.25, n.4/5, p.170-176, 2004.

INSTITUTO BRASILEIRO DE INFORMAÇÃO EM CIÊNCIA E TECNOLOGIA IBICT. Edital de chamada FINEP/PCAL/XBDB No 001/2009. Brasília, 2009. Disponível

em: $<$ http://www.ibict.br/anexos noticias/EDITAL distrib epto pcal xbdb 2 2009.doc>. Acesso em: 15 mar. 2009.

Notícias.

Disponível

em:

<http://www.ibict.br/noticia.php?id=643>. Acesso em: 4 jan. 2010.

KEEN, P. Value analysis: justifying decision support systems. MIS Quarterly, v.5, n.1, p.1-15, 1981.

OPEN ARCHIVES FORUM. Main Technical Ideas of OAI-PMH. 2009. Diponível em: <http://www.oaforum.org/tutorial/english/page3.htm>. Acesso em: 23 jan. 2009.

RUH, A. W.; MAGINNIS, F. X. BROWN, W. J. Enterprise application integration. Nova York: John Wiley \& Sons, 211 p., 2001.

SCIARRETTA, T. Transações ultrarrápidas chegam ao Brasil. Folha de $S$. Paulo, São Paulo, 7 ago. 2009. Dinheiro, p.b8.

SMITH, M. DSpace: an open source institutional repository for digital material. D-Lib Magazine, v. 8, n. 10, Oct. 2002. Disponível em: <http://www.dlib.org/dlib/october02/10inbrief.html>. Acesso em: 22 set. 2008. 